УДК 502.174.1

DOI 10.30679/2219-5335-2022-1-73-263-271

СРАВНИТЕЛЬНАЯ

ХАРАКТЕРИСТИКА ВЛИЯНИЯ

СПОСОБА ХРАНЕНИЯ

ВИНОГРАДНЫХ ВЫЖИМОК

НА СОДЕРЖАНИЕ

ПОЛИФЕНОЛЬНЫХ ВЕЩЕСТВ И ВИТАМИНА С

Семиряжко Елизавета Сергеевна ${ }^{1}$ младший научный сотрудник отдела пищевых технологий, контроля качества и стандартизации e-mail: e.glazacheva@yandex.ru

Горлов Сергей Михайлович ${ }^{2}$ канд. техн. наук, доцент первый заместитель директора e-mail: gorlov76@list.ru

Яковлева Татьяна Викторовна ${ }^{1}$ канд. техн. наук, доцент

ст. научный сотрудник отдела хранения и комплексной переработки сельскохозяйственного сырья e-mail: yakovleva_yy@mail.ru

Тягущева Анна Анатольевна ${ }^{1}$ младший научный сотрудник отдела пищевых технологий, контроля качества и стандартизации e-mail: 777Any777 @ mail.ru

${ }^{1}$ Краснодарский научноисследовательский институт хранения и переработки сельскохозяйственной продукции филиал Федерального государственного бюджетного научного учреждения «Северо-Кавказский федеральный научный центр садоводства, виноградарства, виноделия», Краснодар, Россия

${ }^{2}$ Федеральное государственное бюджетное научное учреждение «Северо-Кавказский федеральный научный центр садоводства, виноградарства, виноделия», Краснодар, Россия
UDC 502.174.1

DOI 10.30679/2219-5335-2022-1-73-263-271

\section{COMPARATIVE \\ CHARACTERISTICS \\ OF THE EFFECT OF THE METHOD \\ OF STORING GRAPE POMACE ON THE CONTENT \\ OF POLYPHENOLIC SUBSTANCES AND VITAMIN C}

Semiryazhko Elizaveta Sergeevna ${ }^{1}$

Junior Research Associate of Food Technology, Quality Control and Standardization Department e-mail: e.glazacheva@yandex.ru

Gorlov Sergey Mikhailovich ${ }^{2}$

Cand. Tech. Sci., Associate Professor First Deputy Director

e-mail: gorlov76@list.ru

Yakovleva Tatiana Viktorovna ${ }^{1}$

Cand. Tech. Sci., Associate Professor

Senior Research Associate of Storage and Complex processing of Agricultural Raw materials Department e-mail: yakovleva_yy@mail.ru

Tyagushcheva Anna Anatolyevna ${ }^{1}$ Junior Research Associate of Food Technology, Quality Control and Standardization Department e-mail: 777Any777@mail.ru

${ }^{1}$ Krasnodar Research Institute of Agricultural Product

Storage and Processing -

Branch of Federal State Budgetary

Scientific Institution

«North-Caucasus

Federal Scientific Center

of Horticulture,

Viticulture, Wine-making»,

Krasnodar, Russia

${ }^{2}$ Federal State Budget

Scientific Institution

«North Caucasian Federal

Scientific Center of Horticulture,

Viticulture, Wine-making»,

Krasnodar, Russia 
В процессе виноделия образуется большое количество побочных продуктов (виноградные выжимки), в составе которых содержится большое количество биологически активных веществ. С целью сохранения данных веществ и замедления микробного гниения виноградные выжимки хранят в сухом или замороженном виде. Исходя из этого, целью работы было изучение влияния способов хранения виноградных выжимок на содержание полифенолов и витамина С. В качестве объектов исследования были выбраны виноградные выжимки красных сортов винограда Каберне Совиньон и Казачка, выращенного в условиях Анапо-Таманской зоны. Все образцы выжимок были получены после прессования, часть которых была высушена при оптимальной температуре $45^{\circ} \mathrm{C}$ для сохранения структуры виноградной выжимки в течение 6 часов, а часть была заморожена при температуре минус $15^{\circ} \mathrm{C}$, исходя из анализа научной литературы. Анализ полученных данных исследований показал, что процессы высушивания и замораживания неодинаково влияют на изменение полифенольных веществ и витамина $\mathrm{C}$, содержащихся в выжимках. Общее содержание полифенолов увеличивается как при высушивании (Каберне Совиньон на 10,6\%, Казачка -2,5 \%), так и при замораживании (Каберне Совиньон на $27,7 \%$, Казачка - 12,7 \%), а содержание витамина С уменьшается (при высушивании: Каберне Совиньон на 26,6 \%, Казачка -37,9 \%, при замораживании: Каберне Совиньон на 21,9\%, Казачка - 36,6 \%), вследствие его разрушения под действием температуры. Таким образом, замораживание виноградных выжимок является более предпочтительным способом хранения, так как сохранение полифенольных веществ может повысить их потенциальное использование.

Ключевые слова: ВИНОГРАДНЫЕ ВЫЖИМКИ, ХРАНЕНИЕ, ПОЛИФЕНОЛЫ, ВИТАМИН С
The winemaking process produces a large number of by-products (grape pomace), which contain a large number of biologically active substances. In order to preserve these substances and to slow down microbial putrefaction, grape pomace is stored dry or frozen. On this basis, the aim of the work was to study the effect of grape pomace storage methods on the polyphenol and vitamin $\mathrm{C}$ content. The objects of the study were grape pomace of red varieties of Cabernet and Kazachka grapes grown in the conditions of the Anapo-Taman zone.

All the pomace samples were obtained after pressing, a part of which was dried at an optimum temperature of $45^{\circ} \mathrm{C}$ to preserve the structure of the grape pomace for 6 hours, and a part was frozen at minus $15^{\circ} \mathrm{C}$, based on an analysis of the scientific literature. Analysis of the research data obtained showed that the drying and freezing processes had different effects on the change of polyphenolic substances and vitamin $\mathrm{C}$ contained in the pomace. The total content of polyphenols increases both during drying (10.6\% for Cabernet and $2.5 \%$ for Kazacka) and freezing (27.7\% for Cabernet and $12.7 \%$ for Kazacka). Vitamin C content decreases (dried: $26.6 \%$ for Cabernet, $37.9 \%$ for Kazacka, frozen: $21.9 \%$ for Cabernet, $36.6 \%$ for Kazacka), being destroyed by temperature. Thus, freezing of grape extracts is a preferable storage method, since preservation of polyphenolic substances can increase their potential use.

Keywords: GRAPE POMACE, STORAGE, POLYPHENOLS, VITAMIN C 
Плодоводство и виноградарство Юга России № 73(1), 2022 г.

Введение. В процессе виноделия образуется большое количество побочных продуктов, хранение или утилизация которых является серьезной проблемой как с экологической, так и с экономической точки зрения. Основной побочный продукт винодельческой промышленности - виноградные выжимки, составляют от 10 до 30 \% массы прессованного винограда [1-3].

В последнее время, данное сырье вызывает большой интерес, поскольку является источником полезных веществ, а именно полифенолов, обладающих антиоксидантными свойствами [4-7]. Кожица винограда, в отличие от его мякоти, является потенциальным источником полифенольных веществ и различных витаминов. Виноградные выжимки большинства красных сортов винограда содержат большое количество антоцианов и флавонолов (в пересчете на антоцианидины в количестве 30-750 мг/100 г сырого веса) [8].

Многие научные работы посвящены изучению свойств фенольных соединений, в связи с чем возрастает интерес применения виноградных выжимок как рецептурного компонента в составе функциональных продуктов питания [3, 9-12]. Однако виноградные выжимки часто подвергаются микробному гниению, что требует быстрого решения по их способу хранения [13]. Как известно, существуют способы хранения виноградных выжимок с целью дальнейшего применения с использованием процессов высушивания и замораживания $[8,14,15]$. В некоторых научных работах были проведены исследования влияния высушивания виноградных выжимок на содержание полифенольных веществ, результаты которых противоречивы [16-20]. При изучении работ российских ученых аналогичных исследований обнаружено не было. Исходя из этого, целью работы являлось исследование влияния процессов высушивания и замораживания свежих виноградных выжимок на содержание полифенольных веществ 
Плодоводство и виноградарство Юга России № 73(1), 2022 г.

и витамина $\mathrm{C}$, с целью дальнейшего использования в рецептурах функциональных продуктов питания.

Объекты и методы исследования. В качестве объектов исследования были использованы выжимки винограда сорта Каберне Совиньон и Казачка, произведенные винодельческим заводом Краснодарского края «Союз-вино». Виноград сорта Каберне Совиньон и Казачка выращивали в условиях Анапо-Таманской зоны, сбор урожая проводили в 2021 году. Все образцы выжимок были получены после прессования, часть которых была высушена при оптимальной температуре $45{ }^{\circ} \mathrm{C}$ для сохранения структуры виноградной выжимки в течение 6 часов, а часть была заморожена при температуре минус $15^{\circ} \mathrm{C}$, исходя из анализа научной литературы $[8,14]$.

В подготовленных образцах проводили опеределение содержания общих полифенольных веществ и витамина С. Содержание общих полифенолов определяли колометрическим методом с использованием реактива Фолина-Дениса [21]. Содержание витамина С определяли йодометрическим методом [22].

Обсуждение результатов. Определение содержания общих полифенольных веществ и витамина С в свежих виноградных выжимках сорта Каберне Совиньон и Казачка представлены в таблице 1.

Таблица 1 - Содержание полифенольных веществ и витамина $\mathrm{C}$ в свежих виноградных выжимках сорта Каберне Совиньон и Казачка

\begin{tabular}{|l|c|c|}
\hline \multicolumn{1}{|c|}{ Наименование сорта } & $\begin{array}{c}\text { Общее содержание } \\
\text { полифенолов, мг/100 г }\end{array}$ & $\begin{array}{c}\text { Общее содержание } \\
\text { витамина С, мг/100 г }\end{array}$ \\
\hline Сорт винограда Каберне Совиньон & 310,6 & $3,6 \pm 0,1$ \\
\hline Сорт винограда Казачка & 454,1 & $7,8 \pm 0,1$ \\
\hline
\end{tabular}

В результате определения общего содержания полифенольных веществ установлено, что сорт винограда Казачка характеризуется повышен- 
Плодоводство и виноградарство Юга России № 73(1), 2022 г.

ным содержанием полифенолов $(454,1$ мг/100 г) и витамина С (7,8 мг/100 г) по сравнению с сортом Каберне Совиньон.

Анализ содержания общих полифенольных веществ и витамина С в высушенных виноградных выжимках сортов винограда Каберне Совиньон и Казачка представлен в таблице 2.

Таблица 2 - Содержание полифенольных веществ и витамина С в высушенных виноградных выжимках сорта Каберне Совиньон и Казачка

\begin{tabular}{|l|c|c|}
\hline \multicolumn{1}{|c|}{ Наименование сорта } & $\begin{array}{c}\text { Общее содержание } \\
\text { полифенолов, мг/100 г }\end{array}$ & $\begin{array}{c}\text { Общее содержание } \\
\text { витамина С, мг/100 г }\end{array}$ \\
\hline \multicolumn{2}{|c|}{ Сухие виноградные выжимки } \\
\hline Сорт винограда Каберне Совиньон & 343,8 & $2,6 \pm 0,1$ \\
\hline Сорт винограда Казачка & 465,9 & $4,8 \pm 0,1$ \\
\hline
\end{tabular}

Исходя из полученных данных, установлено, что общее содержание полифенолов в высушенных виноградных выжимках увеличивается относительно свежего виноградного сырья (Каберне Совиньон на 10,6 \%, Казачка на 2,5 \%), однако высушивание губительно влияет на содержание витамина С (Каберне Совиньон - уменьшение на 26,6 \%, Казачка - 37,9 \%), так как происходит его разрушение при термической обработке.

Анализ содержания общих полифенольных веществ и витамина С в замороженных виноградных выжимках сорта Каберне Совиньон и Казачка представлен в таблице 3.

Таблица 3 - Содержание полифенольных веществ и витамина С в замороженных виноградных выжимках сорта Каберне Совиньон и Казачка

\begin{tabular}{|c|c|c|}
\hline Наименование сорта & $\begin{array}{c}\text { Общее содержание } \\
\text { полифенолов, мг/100 г }\end{array}$ & $\begin{array}{c}\text { Общее содержание } \\
\text { витамина С, мг/100 г }\end{array}$ \\
\hline \multicolumn{3}{|c|}{ Замороженные виноградные выжимки } \\
\hline Сорт винограда Каберне Совиньон & 396,7 & $2,8 \pm 0,1$ \\
\hline Сорт винограда Казачка & 510,2 & $4,9 \pm 0,1$ \\
\hline
\end{tabular}

Исходя из данных, представленных в таблице 3, установлено, что процесс замораживания также положительно влияет на содержание полифенолов в виноградных выжимках. В выжимках винограда сорта Казачка количество полифенолов увеличилось на 12,7 \%, в выжимках сорта Каберне 
Плодоводство и виноградарство Юга России № 73(1), 2022 г.

Совиньон на 27,7 \%. Количество витамина С уменьшилось аналогично процессу высушивания (Каберне Совиньон на 21,9%, Казачка - 36,6 \%).

Анализ полученных данных исследований показал, что процессы высушивания и замораживания неодинаково влияют на изменение органических соединений (полифенолов и витамина С), содержащихся в выжимках.

Bbыводы. Основываясь на результатах, описанных выше, можно сделать вывод, что хранение виноградных выжимок в сухом и замороженном состоянии оказывает положительное влияние на содержание полифенольных веществ. Во всех анализируемых образцах виноградных выжимок сорта Каберне Совиньон и Казачка содержание полифенолов было выше, чем в свежем сырье. Однако изучаемые процессы негативно влияют на сохранение витамина С. Поскольку в процессе замораживания происходит увеличение количества полифенолов в виноградных выжимках, данный процесс является более предпочтительным способом хранения. Увеличение количества таких органических соединений, как полифенольные вещества, может повысить потенциальное использование виноградных выжимок в качестве функциональных добавок в питании для обогащения продуктов массового потребления.

\section{Литература}

1. Ilyas T., Chowdhary P., D. Chaurasia, Gnansounou E., Pandey A., Chaturvedi D. Sustainable green processing of grape pomace for the production of value-added products: An overview // Environmental Technology \& Innovation. 2021. V. 23. P. 101.

2. Горлов С.М., Першакова Т.В., Семиряжко Е.С., Тягущева А.А. Биологизация интенсификационных процессов переработки вторичных ресурсов винограда [Электронный ресурс] // Политематический сетевой электронный научный журнал Кубанского государственного аграрного университета. 2021. № 168. C.186-194. URL: https://www.elibrary.ru/item.asp?id=45849130 (дата обращения 17.12.2021).

3. Hang Y. D., Woodams E. E. Grape pomace: A novel substrate for microbial production of citric acid [Электронный pecypc] // Biotechnology Letters. 1985. V. 7. P. 253-254. URL:https://link.springer.com/article/10.1007/BF01042372 (дата обращения 20. 12.2021).

4. Кривова Л.П., Рыжкова А.Ю. Виноградные выжимки как источник фенольных соединений [Электронный ресурс] // Научно-исследовательские публикации. 2016. № 6 (38). C. 41-47. URL: https://elibrary.ru/item.asp?id=27685284 (дата обращения 20. 12.2021). 
5. Milinčić D. D., Stanisavljević N. S., Ž.Kostić A., Soković S., Kojić M. O. Phenolic compounds and biopotential of grape pomace extracts from Prokupac red grape variety [Электронный ресурс] // LWT. 2021. V. 138. P. 110. URL: DOI:10.1016/j.lwt.2020.110739 (дата обращения 20. 12.2021).

6. Deng Q., Penner M., Zhao Y. Chemical compounds of dietary fiber and polyphenol of five different varieties of wine grape pomace skins [Электронный ресурс] // Food Research International. 2011. № 44 (9). P. 2712-2720. URL: DOI:10.1016/ j.foodres.2011.05.026 (дата обращения 20. 12.2021).

7. Carmona-Jiménez Y., García-Moreno M. V., García-Barroso C. Effect of drying on the phenolic content and antioxidant activity of red grape pomace [Электронный pecypc] // Plant foods for human nutrition. 2018. V. 73. P. 74-81. URL: https://link.springer. com/article/10.1007/s11130-018-0658-1 (дата обращения 15. 12.2021).

8. Shiema A., Kudachikar V.B., Vanajakshi V., Ravi R. Effect of combined preservation techniques on the stability and microbial quality and retention of anthocyanins in grape pomace stored at low temperature [Электронный ресурс] // Journal of Food Science and Technology. 2013. V. 50, p. 332-338. URL: https://link.springer.com/article/10.1007/s13197011-0325-0 (дата обращения 20. 12.2021).

9. Guaita M., Panero L., Motta S., Mangione B., Bosso A. Effects of high-temperature drying on the polyphenolic composition of skins and seeds from red grape pomace [Электронный ресурс] // LWT. 2021. № 145. P. 323. URL: DOI:10.1016/j.lwt.2021.111323 (дата обращения 20. 12.2021).

10. Ageyeva N., Tikhonova A., Burtsev B., Globa E. Physicochemical parameters of grape pomace subject to grape processing technology applied [Электронный pecypc] // E3S Web of Conferences. 2021. № 285. URL: DOI:10.1051/e3sconf/202128505019 (дата обращения 20. 12.2021).

11. Mollica A., Scioli G., Della Valle A.; Cichelli A., Novellino E. Phenolic Analysis and in vitro biological activity of red wine, pomace and grape seeds oil derived from Vitis vinifera L. cv. Montepulciano d'Abruzzo [Электронный ресурс] // Antioxidants. 2021. № 10 (11) URL: DOI:10.3390/antiox10111704 (дата обращения 17. 12.2021).

12. Maner S., Kumar Sharma V, Banerjee V. Wheat flour replacement by wine grape pomace powder positively affects physical, functional and sensory properties of cookies [Электронный ресурс] // Proceedings of the National Academy of Sciences, India Section B:

Biological Sciences. 2017. V. 87, p. 109-113. URL: https://link.springer. com/article/10.1007/s40011-015-0570-5 (дата обращения 17. 12.2021).

13. Meza Y.M., Jiménez J. P., Guzmán N.E., García M.E., Macías M.A., Camacho R.R. Modification on the polyphenols and dietary fiber content of grape pomace by instant controlled pressure drop // Food Chemistry. 2021. № 360. P. 130-135.

14. Макарова Н.В., Стрюкова А.Д., Чигирёва А.В. Влияние замораживания на антиоксидантную активность ягод // Технологии и оборудование химической, биотехнологической и пищевой промышленности. 2013. С. 417-421.

15. Макарова Н. В., Еремеева Н.Б., Игнатова Д.Ф. Влияние технологии экстракции на антиоксидантную активность черноплодной рябины Aronia Melanocarpa, брусники Vaccínium Vitis-Idaea, черники Vaccínium Myrtillus, малины Rubus Idaeus, вишни Prunus Subg. Ctrasus, черной смородины Ribes Nigrum // Вестник Мурманского государственного технического университета. 2019. Т. 22. № 3. С.320-330.

16. Taseri L., Aktaş M., Şevik S., Gülcü M. Determination of Drying Kinetics and Quality Parameters of Grape Pomace Dried with a Heat Pump Dryer [Электронный ресурс] // Food Chemistry. 2018. № 260. P. 152-159. URL: DOI:10.1016/j.foodchem.2018.03.122 (дата обращения 15. 12.2021). 
17. Goula A., Thymiatiz K., Kaderides K. Valorization of grape pomace: Drying behavior and ultrasound extraction of phenolics // Food and Bioproducts Processing. 2016. № 100. P. 132-144.

18. Sáyago-Ayerdi S.G., Brenes A., Goñi I. Effect of grape antioxidant dietary fiber on the lipid oxidation of raw and cooked chicken hamburgers [Электронный pecypc] // LWT-Food Sci Technol. 2009. № 42. P. 971-976. URL: DOI:10.1016/j.lwt.2008.12.006 (дата обращения:17.12.2021).

19. Canalejo D., Guadalupe Z., Martínez-Lapuente L., Ayestarán B., Pérez-Magariño S. Optimization of a method to extract polysaccharides from white grape pomace by-products // Food Chemistry. 2021. V.365. P. 130.

20. Hoye J.C., Ross C.F. Total phenolic content, consumer acceptance, and instrumental analysis of bread made with grape seed flour [Электронный ресурс] // Food Sci. 2011. P. 428-436. URL: https://onlinelibrary.wiley.com/doi/10.1111/j.1750-3841.2011.02324 (дата обращения:17.12.2021).

21. Запрометов М.Н. Основы биохимии фенольных соединений. Учебное пособие для биол. специальностей ун-тов. М., Высш. Школа, 1974. С. 75.

22. Бурштейн А.И. Методы исследования пищевых продуктов. Киев: Госмедиздат УССР, 1963. С. 382-384.

\section{Reference}

1. Ilyas T., Chowdhary P., D. Chaurasia, Gnansounou E., Pandey A., Chaturvedi D. Sustainable green processing of grape pomace for the production of value-added products: An overview // Environmental Technology \& Innovation. 2021. V. 23. P. 101.

2. Gorlov S.M., Pershakova T.V., Semiryazhko E.S., Tyagushcheva A.A. Biologizaciya intensifikacionnyh processov pererabotki vtorichnyh resursov vinograda [Elektronnyj resurs] // Politematicheskij setevoj elektronnyj nauchnyj zhurnal Kubanskogo gosudarstvennogo agrarnogo universiteta. 2021. № 168. S. 186-194. URL: https://www.elibrary.ru/ item.asp?id=45849130 (data obrashcheniya 17. 12.2021).

3. Hang Y. D., Woodams E. E. Grape pomace: A novel substrate for microbial production of citric acid [Elektronnyj resurs] // Biotechnology Letters. 1985. V. 7. P. 253-254. URL: https://link.springer.com/article/10.1007/BF01042372 (data obrashcheniya 20. 12.2021).

4. Krivova L.P., Ryzhkova A.Yu. Vinogradnye vyzhimki kak istochnik fenol'nyh soedinenij [Elektronnyj resurs] // Nauchno-issledovatel'skie publikacii. 2016. № 6 (38). S. 41-47. URL: https://elibrary.ru/item.asp?id=27685284 (data obrashcheniya 20. 12.2021).

5. Milinčić D. D., Stanisavljević N. S., Ž.Kostić A., Soković S., Kojić M. O. Phenolic compounds and biopotential of grape pomace extracts from Prokupac red grape variety [Elektronnyj resurs] // LWT. 2021. V. 138. R. 110. URL: DOI:10.1016/j.lwt.2020.110739 (data obrashcheniya 20. 12.2021).

6. Deng Q., Penner M., Zhao Y. Chemical compounds of dietary fiber and polyphenol of five different varieties of wine grape pomace skins [Elektronnyj resurs] // Food Research International. 2011. № 44 (9). R. 2712-2720. URL: DOI:10.1016/ j.foodres. 2011.05.026 (data obrashcheniya 20. 12.2021).

7. Carmona-Jiménez Y., García-Moreno M. V., García-Barroso C. Effect of drying on the phenolic content and antioxidant activity of red grape pomace [Elektronnyj resurs] // Plant foods for human nutrition. 2018. V. 73. R. 74-81. URL: https://link.springer. com/article/10.1007/s11130-018-0658-1 (data obrashcheniya 15. 12.2021).

8. Shiema A., Kudachikar V.B., Vanajakshi V., Ravi R. Effect of combined preservation techniques on the stability and microbial quality and retention of anthocyanins in grape pomace stored at low temperature [Elektronnyj resurs] // Journal of Food Science and Technology. 2013. V. 50, p. 332-338. URL: https://link.springer.com/article/10.1007/s13197-0110325-0 (data obrashcheniya 20. 12.2021). 
9. Guaita M., Panero L., Motta S., Mangione B., Bosso A. Effects of hightemperature drying on the polyphenolic composition of skins and seeds from red grape pomace [Elektronnyj resurs] // LWT. 2021. № 145. P. 323. URL: DOI: 10.1016/j.lwt.2021.111323 (data obrashcheniya 20. 12.2021).

10. Ageyeva N., Tikhonova A., Burtsev B., Globa E. Physicochemical parameters of grape pomace subject to grape processing technology applied [Elektronnyj resurs] // E3S Web of Conferences. 2021. № 285. URL: DOI:10.1051/e3sconf/202128505019 (data obrashcheniya 20. 12.2021).

11. Mollica A., Scioli G., Della Valle A.; Cichelli A., Novellino E. Phenolic Analysis and in vitro biological activity of red wine, pomace and grape seeds oil derived from Vitis vinifera L. cv. Montepulciano d'Abruzzo [Elektronnyj resurs] // Antioxidants. 2021. № 10 (11) URL: DOI:10.3390/antiox10111704 (data obrashcheniya 17. 12.2021).

12. Maner S., Kumar Sharma V, Banerjee V. Wheat flour replacement by wine grape pomace powder positively affects physical, functional and sensory properties of cookies [Elektronnyj resurs] // Proceedings of the National Academy of Sciences, India Section B: Biological Sciences. 2017. V. 87, p. 109-113. URL: https://link.springer. com/article/10.1007/s40011-015-0570-5 (data obrashcheniya 17. 12.2021).

13. Meza Y.M., Jiménez J. P., Guzmán N.E., García M.E., Macías M.A., Camacho R.R. Modification on the polyphenols and dietary fiber content of grape pomace by instant controlled pressure drop // Food Chemistry. 2021. № 360. R. 130-135.

14. Makarova N.V., Stryukova A.D., Chigiryova A.V. Vliyanie zamorazhivaniya na antioksidantnuyu aktivnost' yagod // Tekhnologii i oborudovanie himicheskoj, biotekhnologicheskoj i pishchevoj promyshlennosti. 2013. S. 417-421.

15. Makarova N. V., Eremeeva N.B., Ignatova D.F. Vliyanie tekhnologii ekstrakcii na antioksidantnuyu aktivnost' chernoplodnoj ryabiny Aronia Melanocarpa, brusniki Vaccínium Vitis-Idaea, cherniki Vaccínium Myrtíllus, maliny Rubus Idaeus, vishni Prunus Subg. Ctrasus, chernoj smorodiny Ribes Nigrum // Vestnik Murmanskogo gosudarstvennogo tekhnicheskogo universiteta. 2019. T. 22. № 3. S.320-330.

16. Taseri L., Aktaş M., Şevik S., Gülcü M. Determination of Drying Kinetics and Quality Parameters of Grape Pomace Dried with a Heat Pump Dryer [Elektronnyj resurs] // Food Chemistry. 2018. № 260. P. 152-159. URL: DOI:10.1016/j.foodchem.2018.03.122 (data obrashcheniya 15. 12.2021).

17. Goula A., Thymiatiz K., Kaderides K. Valorization of grape pomace: Drying behavior and ultrasound extraction of phenolics // Food and Bioproducts Processing. 2016. № 100. P. 132-144.

18. Sáyago-Ayerdi S.G., Brenes A., Goñi I. Effect of grape antioxidant dietary fiber on the lipid oxidation of raw and cooked chicken hamburgers [Elektronnyj resurs] // LWTFood Sci Technol. 2009. № 42. P. 971-976. URL: DOI:10.1016/j.lwt.2008.12.006 (data obrashcheniya:17.12.2021).

19. Canalejo D., Guadalupe Z., Martínez-Lapuente L., Ayestarán B., Pérez-Magariño S. Optimization of a method to extract polysaccharides from white grape pomace by-products // Food Chemistry. 2021. V.365. P. 130.

20. Hoye J.C., Ross C. F. Total phenolic content, consumer acceptance, and instrumental analysis of bread made with grape seed flour [Elektronnyj resurs] // Food Sci. 2011. P. 428-436. URL: https://onlinelibrary.wiley.com/doi/10.1111/j.1750-3841.2011.02324 (data obrashcheniya:17.12.2021).

21. Zaprometov M.N. Osnovy biohimii fenol'nyh soedinenij. Uchebnoe posobie dlya biol. special'nostej un-tov. M., Vyssh. Shkola, 1974. S. 75.

22. Burshtejn A.I. Metody issledovaniya pishchevyh produktov. Kiev: Gosmedizdat USSR, 1963. S. 382-384. 